\title{
Machining Characteristics of Wire Electrical Discharge Machining on Insulating $\mathrm{Si}_{3} \mathrm{~N}_{4}$ Ceramics -Relationship between Electrical Conductive Layer and Machining Characteristics-
}

\author{
Hiromitsu GOTOH*, Takayuki TANI*, and Naotake MOHRI** \\ (Received January 8, 2015)
}

\begin{abstract}
* Department of Industrial Information, Tsukuba University of Technology, Ibaraki 305-8520, Japan
** National Institution for Academic Degrees and University Evaluation, Tokyo 187-8587, Japan
\end{abstract}

\begin{abstract}
In recent years, ceramics materials have found increased use in industry. However, some of them are insulating ceramics that cannot be machined by conventional electrical discharge machining. In this study, we developed a special wire EDM machine for investigating the machining characteristics of insulating ceramics. The machining characteristics of $\mathrm{Si}_{3} \mathrm{~N}_{4}$ insulating ceramics, especially surface roughness, are described. It was confirmed that long pulse discharges are minimally generated under the second cutting conditions where small discharge craters are uniformly formed on the machined surface. The resulting surface roughness was improved down to $4 \mu \mathrm{mRz}$. In addition, a unique process of machining with insulating ceramics, in which the threshold level becomes almost of the same as the voltage between the discharge and power supply positions, was observed.
\end{abstract}

Key words: insulating ceramics, wire electrical discharge machining, $\mathrm{Si}_{3} \mathrm{~N}_{4}$

\section{INTRODUCTION}

Functional ceramics are widely used as constituent materials for precision machinery owing to their strong hardness, high heat resistance, high temperature-corrosion resistance, high wear resistance, and electric insulating capacity. For ceramic machining, ultrasonic, laser-beam, and abrasive jet methods have been used and tested. ${ }^{1)-3)}$ On the other hand, our group has developed an assisting-electrode method-an electrical discharge machining method-for functional ceramics. We have also tested the die-sinking electrical discharge machining technology and wire electrical discharge machining method for various types of ceramics. ${ }^{4-6)}$

In the assisting-electrode method, the surface of a target insulating material is pre-coated with a conductive material, and machining is performed in oil with a positive voltage applied to the said material. A conductive layer is formed on the surface of the insulating work piece and sustains the machining process. Thus, the process of forming a conductive layer greatly influences the machining characteristics.

Today, a conductive layer is widely believed to be formed because "long pulse discharges" are generated. Figure 1 shows the model of a long pulse discharge.

In general, the Iso-pulse method is used to control the duration of electrical discharge. The start time of the discharge is defined at the time point when the voltage drop associated with the discharge current falls below the discharge threshold level, and the

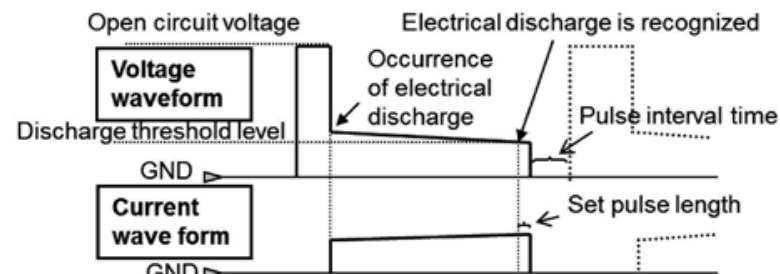

Fig. 1 Model of occurrence of long pulse discharge

discharge duration is subsequently controlled by a pulse voltage at certain duration. An electrical discharge of any length is generated using this control system. However, in the electrical discharge of insulating ceramics, the apparent voltage between electrodes is large because the electrical discharge is triggered through a resistive conductive layer. Therefore, when the occurrence of a discharge is not recognized, the machining equipment may continue to generate a voltage; as a result, the pulse duration of the discharge becomes longer than the set value.

Thus, "long pulse discharge" is a discharge whose duration is longer than the set value, a discharge characteristic of high-resistivity materials such as insulating ceramics and it is not found in normal metal works. Therefore, parameters, e.g., "discharge threshold level," which does not influence the machining characteristics of metal machining, can be an influencing factor in the electrical discharge machining of insulating ceramics.

In this study, the machining target is insulating ceramics. Therefore, the machining mechanism is most likely different from that of electrical discharge 
machining of metals. In a series of earlier studies, commercial electrical discharge machines were remodeled and used in the experiment. However, in the "assisting-electrode method," a conductive-layer formation process is separately required from the removal process. Therefore, dedicated machining equipment that can control various settings is necessary to clarify the various phenomena in the "assisting-electrode method."

In this study, we fabricated a wire discharge machine that can perform electrical discharge machining of insulating ceramics and studied the relationship between the morphology and the machining characteristics of conductive layers that appear on the ceramic surface after machining.

\section{EXPERIMENTAL METHODS}

\subsection{Fabrication of a Wire Discharge Machine in this Research}

In the wire discharge machine fabricated for this study, large importance was attached to three factors: (1) small size and light weight, (2) operability, and (3) scalability. Figure 2 shows the main body of the fabricated modular-type wire discharge machine. The main body of the machining equipment was modularized into three units, namely, (a) machining, (b) wind-up, and (c) wire units, depending on the main functions. Thus, a desktop experimental system was built, which was a scaled-back version of a normal machine in terms of weight and installation space. In addition, because the developed machine had only a small work tank, we could choose from many available base plates to be driven, including the general- and special-purpose models. In addition, the wire electrode had a structure that allowed the use of a commercially available wire bobbin. The arrow in Fig. 2 shows the running direction of the wire electrode.

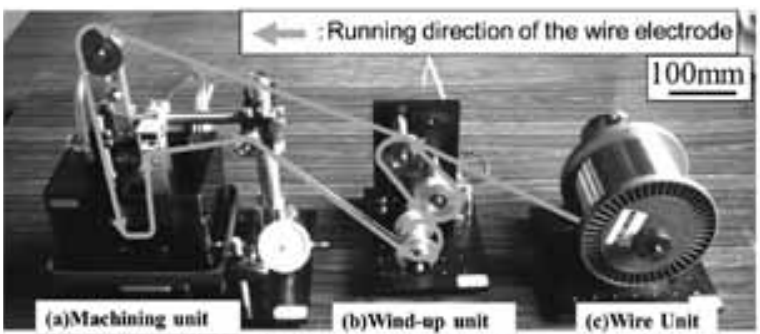

Fig. 2 Modular-type wire discharge machine

Figure 3 shows the circuit of the wire discharge machine. The power supply uses a transistor control circuit. As a general rule, the Iso-pulse method was used, where the discharge pulse duration was controlled similar to that in a commercial machine. In addition, the discharge current was arbitrarily controlled using the internal resistance in the discharge circuit. Servo control was realized between the electrodes by driving the work tank to which the workpiece was attached and by referring to the apparent voltage between the electrodes, as shown in the figure. A stepping motor equipped with a voltage-frequency converter was used to drive the work tank

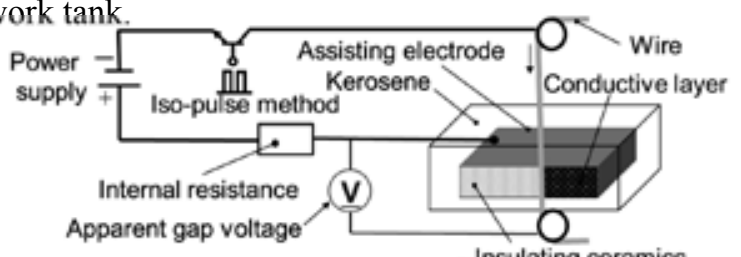

Fig. 3 Circuit $^{\text {?) }}$ Insulating ceramics

\subsection{Test Materials and Experimental Conditions}

Table 1 lists the summary of the structural components of the test material used in the experiment, and Table 2 lists their physical properties. Pressureless sintered 5-mm-thick $\mathrm{Si}_{3} \mathrm{~N}_{4}$ ceramics were used as the samples' material of for making the samples. In addition, a process step was performed to form a conductor layer, which was primarily composed of graphite, on the ceramic surface of the assisting electrode. Table 3 lists the machining conditions used in the experiment. We note that the discharge threshold level was set to $35 \mathrm{~V}$ unless otherwise stated.

Table 1 Components of the test materials [Wt\%]

\begin{tabular}{c|c}
\hline \hline $\mathrm{Si}_{3} \mathrm{~N}_{4}$ & Bal \\
\hline $\mathrm{Al}$ & 3.7 \\
\hline $\mathrm{Y}$ & 3.1 \\
\hline $\mathrm{O}$ & 3.8 \\
\hline $\mathrm{Fe}$ & $<0.1$ \\
\hline $\mathrm{Ca}$ & $<0.2$ \\
\hline $\mathrm{Mg}, \mathrm{Na}, \mathrm{K}$ & $<0.01$ \\
\hline \hline
\end{tabular}

Table 2 Physical properties of the test materials

\begin{tabular}{c|c}
\hline \hline Density & $3.2[\mathrm{~g} / \mathrm{cm} 3]$ \\
\hline Young's modulus & $280[\mathrm{GPa}]$ \\
\hline Melting point & $\begin{array}{c}2100[\mathrm{~K}] \\
(\text { decomposition})\end{array}$ \\
\hline Thermal conductivity & $0.07\left[\mathrm{cal} /\left(\mathrm{cm} \cdot \mathrm{s} \cdot{ }^{\circ} \mathrm{C}\right)\right]$ \\
\hline $\begin{array}{c}\text { Thermal shock } \\
\text { resistance: } \Delta \mathrm{T}\end{array}$ & $770\left[{ }^{\circ} \mathrm{C}\right]$ \\
\hline Hardness & $1900[\mathrm{HV}]$ \\
\hline Bending strength & $800[\mathrm{MPa}]$ \\
\hline $\begin{array}{c}\text { Thermal expansion } \\
\text { coefficient }\end{array}$ & $3.5\left[10^{\left.-6 /{ }^{\circ} \mathrm{C}\right]}\right.$ \\
\hline \hline
\end{tabular}


Table 3 Machining conditions

\begin{tabular}{c|c}
\hline \hline Open circuit voltage: $U_{i}$ & $70[\mathrm{~V}]$ \\
\hline Set discharge current: $i_{e}$ & $1.0-4.9[\mathrm{~A}]$ \\
\hline Pulse width: $t_{e}$ & $1,4,8,10[\mu \mathrm{s}]$ \\
\hline$D . F$. & $20,25,33[\%]$ \\
\hline Discharge threshold level: $V_{t h}$ & $25-55[\mathrm{~V}]$ \\
\hline Wire tension: $W T$ & $100[\mathrm{gf}]$ \\
\hline \hline
\end{tabular}

\section{INVESTIGATION OF WIRE ELECTRICAL DISCHARGE FINISHING}

\subsection{Influence of the Set Discharge Current}

The influence of the set discharge current on the machining speed was investigated by changing the internal resistance. Figure 4 shows the experimental results. The machining speed increased with the discharge current. On the other hand, the surface roughness increased with the discharge current up to more than $40 \mu \mathrm{m} \cdot \mathrm{Rz}$ at over $4 \mathrm{~A}$. Figure 5 shows the scanning electron microscope (SEM) images of the conductive layer formed on the ceramic surface after the machining. A conductive layer with a wavy-shaped surface was formed when the discharge current was set to a large value. This result indicates why the surface became extremely rough.

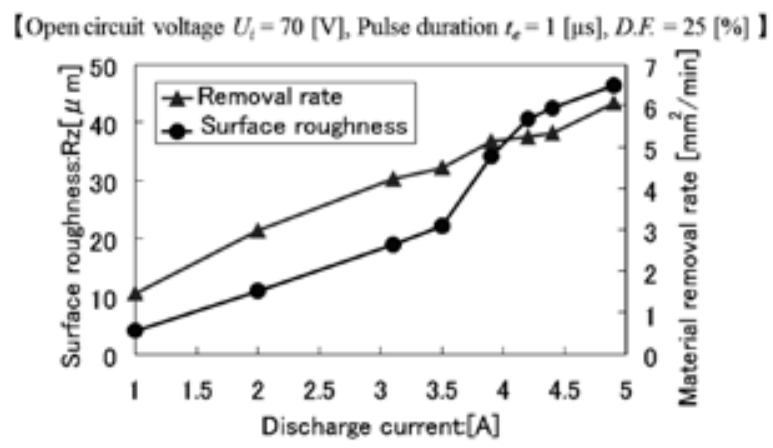

Fig. 4 Influence of discharge current

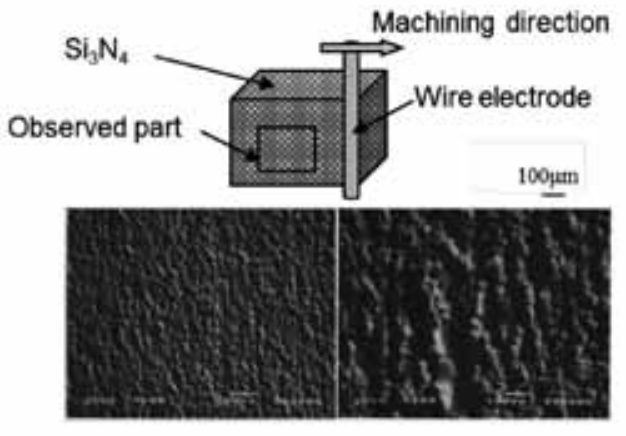

(a) $1.0 \mathrm{~A}$

(b) $3.9 \mathrm{~A}$

Fig. 5 SEM images of conductive layer

\subsection{Finish Cut (Second finishing cut)}

When a larger discharge current was set, the machining speed increased, but the surface morphology was degraded. We believe that the second finishing cut, often used for metal finishing, is effective for efficiently improving the surface roughness. In this section, we discuss the machining characteristics of the second cut for a better finish of $\mathrm{Si}_{3} \mathrm{~N}_{4}$. Table 4 lists the machining conditions used in the second-cut process. We note here that the second cut used condition "3.9 A," as shown in Fig. 5(b).

Table 4 Machining finishing conditions

\begin{tabular}{l|c}
\hline \hline Open circuit voltage: $U_{i}[\mathrm{~V}]$ & 70 \\
\hline Discharge current: $i_{e}[\mathrm{~A}]$ & $0.5,1.0,1.5$ \\
\hline Offset $[\mu \mathrm{m}]$ & $0,30,50,100$ \\
\hline \hline
\end{tabular}

The second cut was investigated using the offset and discharge current as parameters. Figure 6 shows the results. With an offset value of 30,50 , or $100 \mu \mathrm{m}$, the surface roughness improved using a lower discharge current. We note here that the figure does not show a "0" offset because it produces almost no discharge and thus does not contribute to the improvement in the surface roughness.

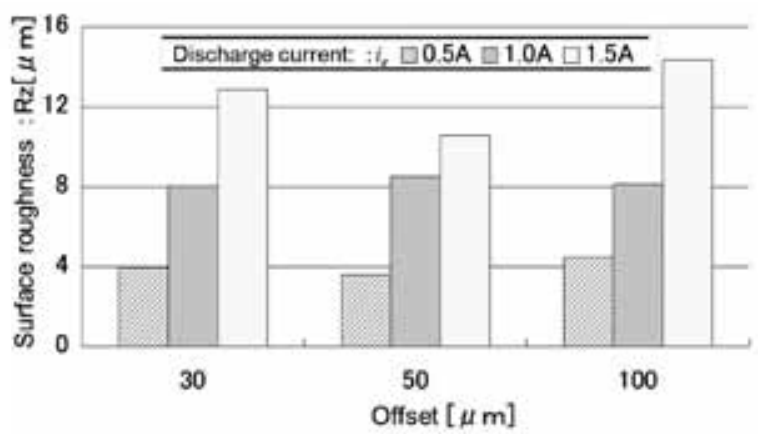

Fig. 6 Finish cut

Figure 7 shows the occurrence frequency of the long pulse discharge for the first and second cuts (offset: $50 \mu \mathrm{m}$ ) against the pulse duration, as well as the surface SEM images. The solid line shows the percentage of the occurrence frequency of the electrical discharge against the pulse width. Further, the dashed line shows the time ratio of the waveform obtained by multiplying the pulse duration and the occurrence frequency of the electrical discharge. In the first cut, the figure shows the existence of long pulse discharges that was over 100 times the set discharge pulse width. We further confirm that a conductive layer with a wavy-shaped pattern was formed parallel to the running direction of the wire. 

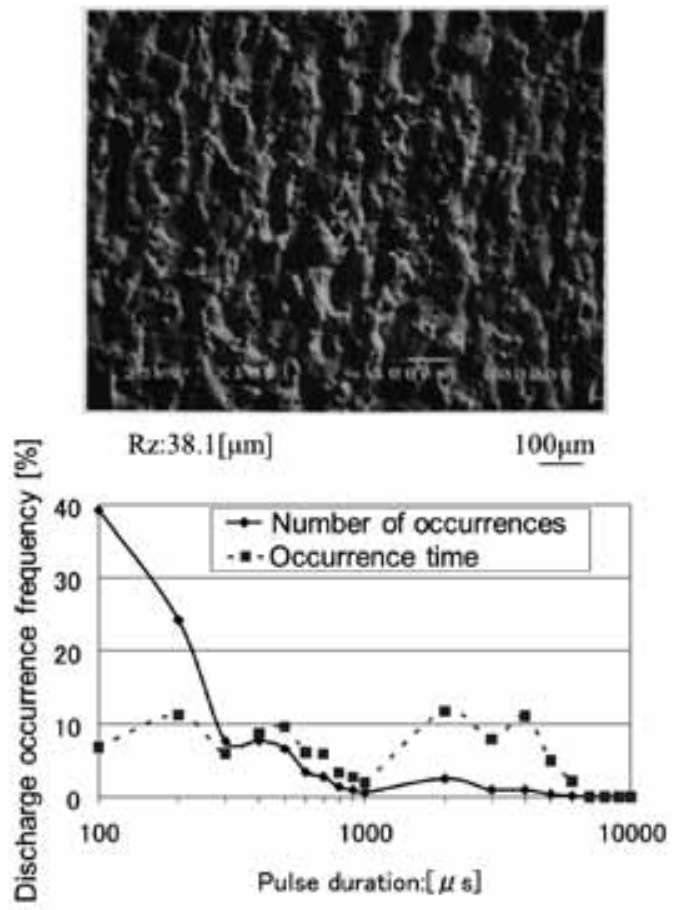

(a) First cut (discharge current: $3.9 \mathrm{~A}$ )
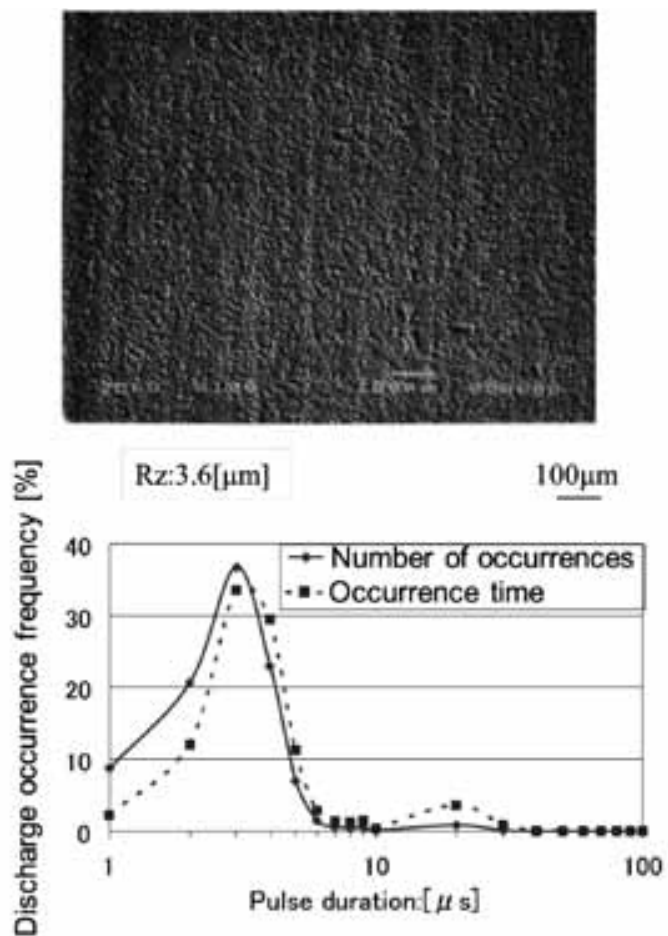

(b) Second cut (discharge current: $0.5 \mathrm{~A}$ )

Fig. 7 Classification of discharge waveforms
In the second cut, long pulse discharges of over 100 times did not occur, and no surface conductive layer with a wavy-shaped pattern was present, in contrast to that found in the first cut.

To observe the ceramic surface, the conductive layer that appeared on the surface of the work piece was removed using a shot-peening process after the electrical discharge machining. Figure 8 shows the surface morphology after the machining. When the shot-peening process was used on the first cut surface, the surface roughness was greatly reduced, but undulation remained. On the other hand, when the shot-peening process was used on the second cut surface, the surface roughness became almost non-existent.

The fact that long pulse discharges were rarely observed after the second cut and the surface condition was not improved by the shot-peening process suggests that the main function of the second cut is to remove the conductive layer formed in the first cut.

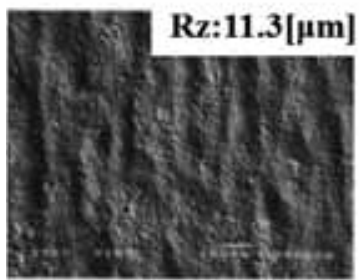

(a) First cut

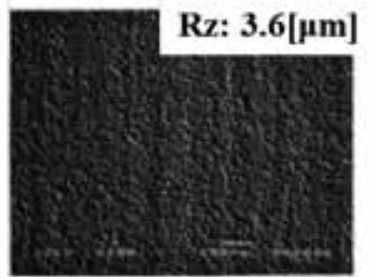

$100 \mu \mathrm{m}$

(b) Second cut
Fig. 8 After the shot-peening machining

\section{INFLUENCE OF THE DISCHARGE THRESHOLD LEVEL}

Because the discharge voltage for metal machining is approximately $20 \mathrm{~V}$, the discharge threshold level scarcely affects the machining characteristics when set larger than $20 \mathrm{~V}$. However, in the discharge process for insulating ceramics, it could affect the machining characteristics because the apparent discharge voltage tends to be high and produces long pulse discharges.

Shin et al. have reported the influence of discharge threshold level in the discharge machining of insulating ceramics using the die-sinking electrical discharge technology, and the machining speed becomes low but the surface morphology is improved when a higher discharge threshold level is used. ${ }^{8)}$ Therefore, we examined the morphology of the conductive layer formed with different discharge threshold levels and studied the difference between the die-sinking electrical discharge technology and the wire electrical discharge method. 


\subsection{Machining Speed and Surface Roughness}

Figure 9 shows the machining speed as a function of the discharge threshold level, as well as the SEM images and surface roughness of the conductive layer on the ceramic surface. The machining speed became high and the surface became rough when the discharge threshold level was set to low. On the other hand, the machining speed became low but the surface became smooth when the discharge threshold level was set to high.

In this experiment, we replicated the phenomenon observed using the sinking electrical discharge technology as reported by Shin et al.

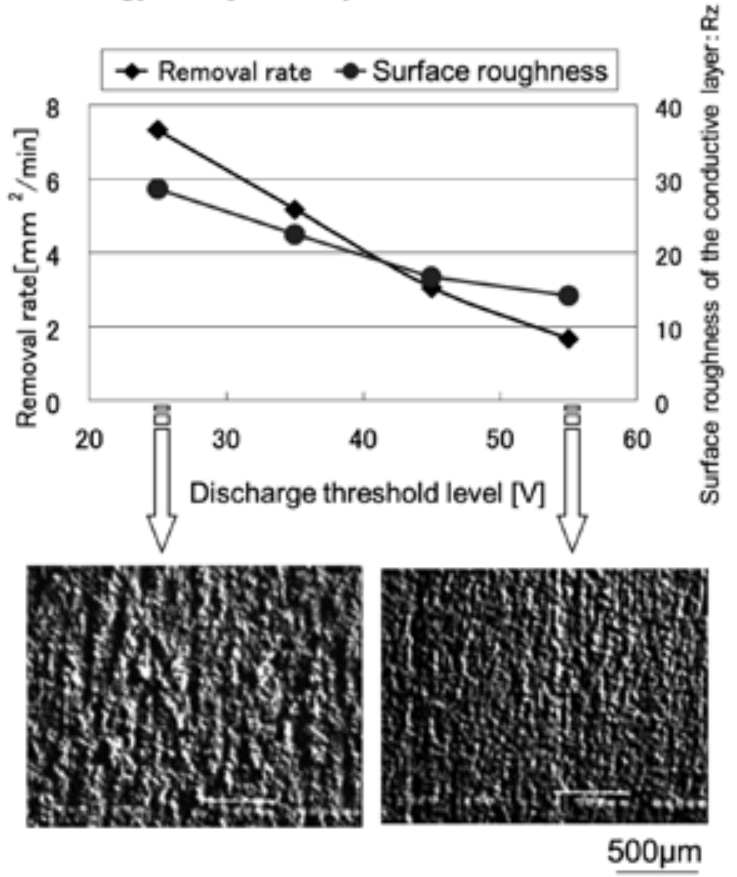

(a) Discharge threshold level: $25 \mathrm{~V}$ (b) Discharge threshold level: $55 \mathrm{~V}$

Fig. 9 Removal rate and surface roughness of the conductive layer

\subsection{Observation of the Discharge Waveform}

Figures 10(a) and (b) show the typical discharge waveforms observed with different discharge threshold levels.

Figure 10(a) shows that when a discharge threshold level of $25 \mathrm{~V}$ was used, the apparent discharge voltage was approximately $25 \mathrm{~V}$. On the other hand, Fig. 10(b) shows that when a discharge threshold level of $55 \mathrm{~V}$ was used, the apparent discharge voltage was approximately $55 \mathrm{~V}$, which is close to the set value of the discharge threshold level. In addition, in the case when the discharge threshold level of $55 \mathrm{~V}$ was switched to $25 \mathrm{~V}$, the discharge voltage also switched to approximately $25 \mathrm{~V}$ after several seconds. From this result, the apparent discharge voltage and current (and thus the machining characteristics) clearly depend on the set value of the discharge threshold level.

\subsection{Difference from the Discharge Method with an External Resistance of the Conductive Material}

According to the earlier discussion, we have verified the phenomenon that in the discharge process of insulating ceramics, the apparent discharge voltage depends on the setting of the discharge threshold level. Therefore, an external resistance was inserted outside the metal (S50C) so that the apparent discharge voltage would be equal to that in the machining of the insulating ceramics, as shown in Fig. 11. By observing the waveforms, we examined the difference between normal machining of the insulating ceramics and the machining of a metal material in series with an external resistance. Table 5 lists the machining conditions.

Table 5 Machining conditions

\begin{tabular}{c|c}
\hline \hline Open circuit voltage: $U_{i}$ & $70[\mathrm{~V}]$ \\
\hline External resistance & $20[\Omega]$ \\
\hline Pulse width $t_{e}$ & $10[\mu \mathrm{s}]$ \\
\hline$D . F$. & $20[\%]$ \\
\hline Discharge threshold level: $V_{t h}$ & $25,55[\mathrm{~V}]$ \\
\hline Wire tension: $W T$ & $100[\mathrm{gf}]$ \\
\hline \hline
\end{tabular}

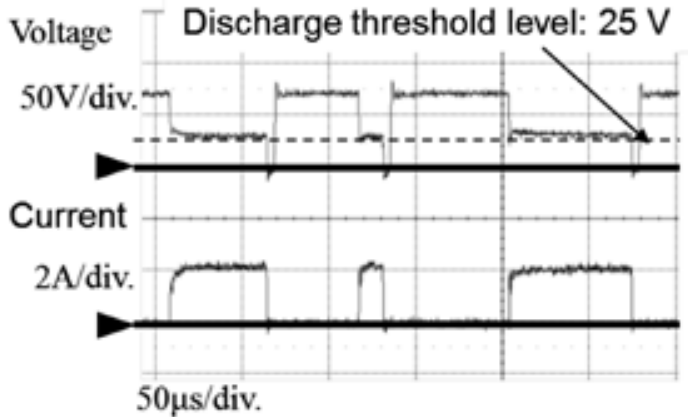

(a) Discharge threshold level: $25 \mathrm{~V}$

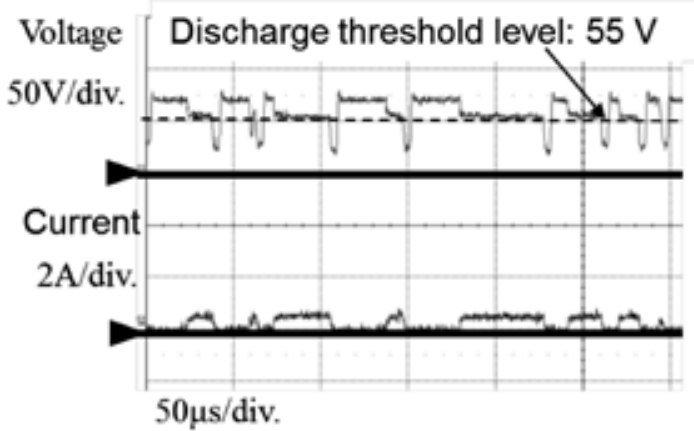

(b) Discharge threshold level: $55 \mathrm{~V}$

Fig. 10 Typical discharge waveforms observed during machining 


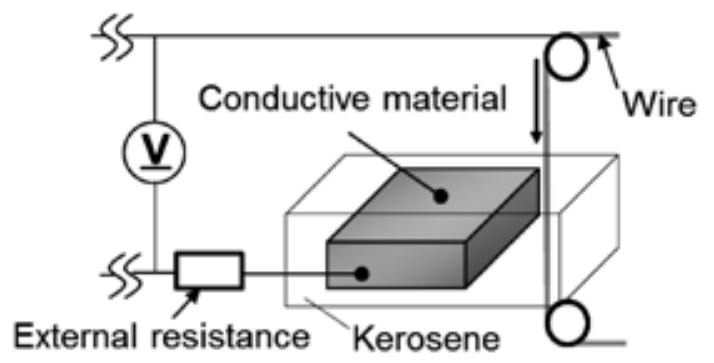

Fig. 11 Insertion of an external resistance

Figure 12(a) shows the discharge waveform of the metal machining with an external resistance, and Fig. 12(b) shows the discharge waveform of the machining of insulating ceramics. Figure 12(a) shows that in the electrical discharge machining with an external resistance, when the apparent discharge voltage was greater than the discharge threshold level, the electrical discharge voltage did not decrease, meaning that the voltage was continuously applied. On the other hand, Fig. 12(b) shows that in the machining of insulating ceramics, a long pulse discharge was generated, and the discharge voltage gradually decreased while the discharge was sustained.

Therefore, the electrical discharge voltage gradually decreased during the electrical discharge machining of insulating ceramics. The change in the resistivity of the conductive layer is likely the mechanism that causes such phenomenon.

Therefore, we evaluated the temperature dependence of the surface resistivity of the conductive layer formed after machining. Figure 13 shows the relationship between the surface resistivity of the conductive layer and the temperature. The surface resistivity of the conductive layer decreased as the temperature increased.

The chief components of the conductive layer formed on the ceramic surface are considered to be highly disordered carbon, silicon, and silicon carbide $(\alpha-\mathrm{SiC})$, which constitute the work piece. ${ }^{9), 10)}$ In this case, the temperature coefficient in the semiconductors and insulators is generally negative and is certainly negative in carbon. ${ }^{11)}$ We consider that the heat generated by long pulse discharges, which are influenced by the components of the conductive layer, is the reason why the temperature of the conductive layer increases and the resistivity decreases.

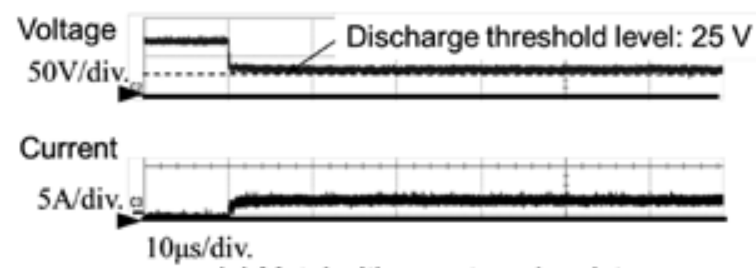

(a) Metal with an external resistance

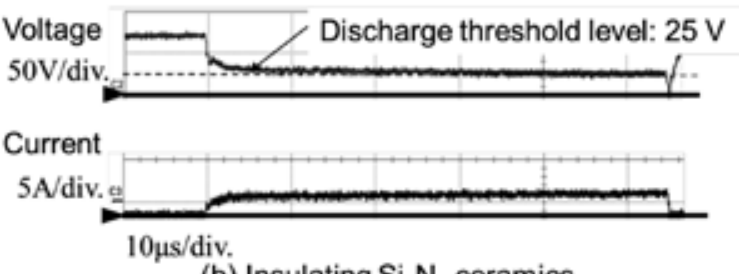

(b) Insulating $\mathrm{Si}_{3} \mathrm{~N}_{4}$ ceramics

Fig. 12 Comparison of the discharge waveforms (discharge threshold level: $25 \mathrm{~V}$ )

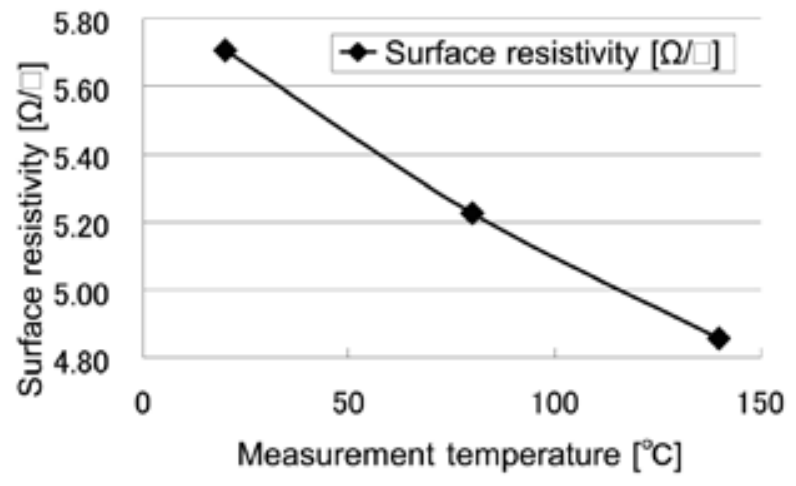

Fig. 13 Relationship between the surface resistivity and temperature of the conductive layer

\subsection{Layer Formation State}

We measured the thickness of the conductive layers formed with different discharge threshold levels. Figure 14 shows the measured thicknesses of the conductive layers. Figure 14(a) shows that the shot-peening process was applied to half the area of the deposited conductive layer, and the cross-sectional profile was then measured. Figure 14(b) shows that a conductive surface layer of approximately $15 \mu \mathrm{m}$ was formed when a discharge threshold level of $25 \mathrm{~V}$ was used in the machining. On the other hand, the thickness of the conductive layer formed with a discharge threshold level of $55 \mathrm{~V}$ was less than $5 \mu \mathrm{m}$; here, the measurement was difficult. 


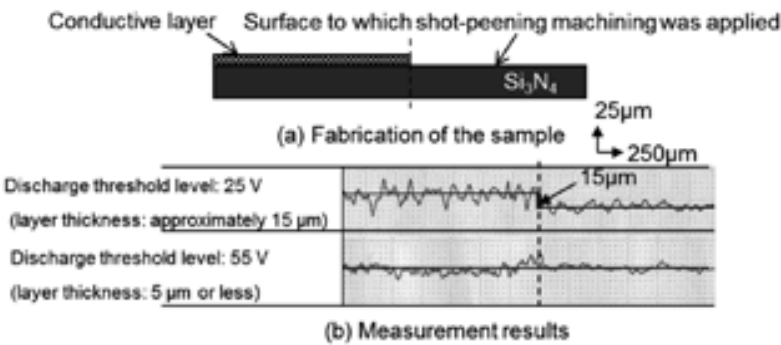

Fig. 14 Thickness of the conductive layer

Subsequently, using a low-resistivity meter (Mitsubishi Chemical Co., Ltd.; Loresta-GP) and the discharge threshold level as a parameter, we evaluated the surface resistivity of the conductive layer formed during the machining. Figure 15 shows the measurement results. The surface resistivity became low when the discharge threshold level was set to low for the machining. We thus show that the resistance of the conductive layer depends on the discharge threshold level.

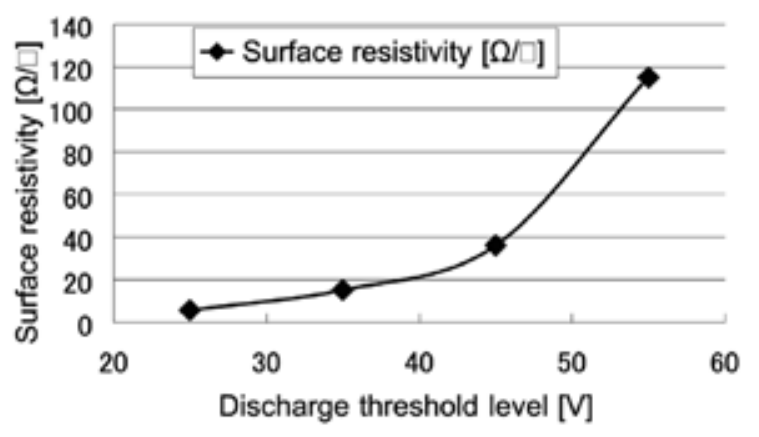

Fig. 15 Surface resistivity of the conductive layer

\subsection{Consideration of the Layer Formation Process}

Figure 16 schematically shows the discharge waveform observed while the discharge threshold level was changed. Figure 16(a) shows that a long pulse discharge was generated when, in the discharge waveform (in the transition region) at the start of the electrical discharge machining, the apparent discharge voltage was larger than the discharge threshold level. We consider that a conductive layer was formed near the area where the electrical discharge occurred, and the resistance became moderately low because of the occurrence of a long pulse discharge.

Figure 16(b) shows that when the discharge threshold level for machining was set to high, the conductive layer formed on the surface was thin, and the surface resistivity remained high. As a result, the apparent discharge voltage also became high. On the other hand, Figure 16(c) shows that when the discharge threshold level was set to low, the conductive layer became thick, and both the surface resistivity and apparent discharge voltage became low.

In summary, we believe that in the discharge process of insulating $\mathrm{Si}_{3} \mathrm{~N}_{4}$ ceramics, we can control the machining state by controlling the discharge threshold level.

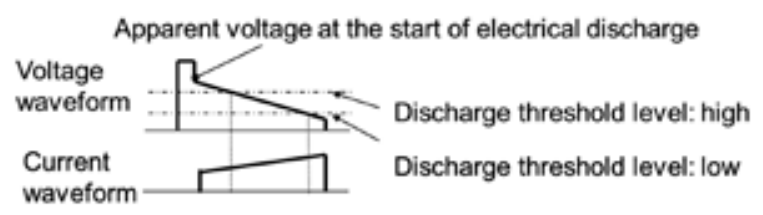

(a) Relationship between long pulse discharge and discharge threshold level

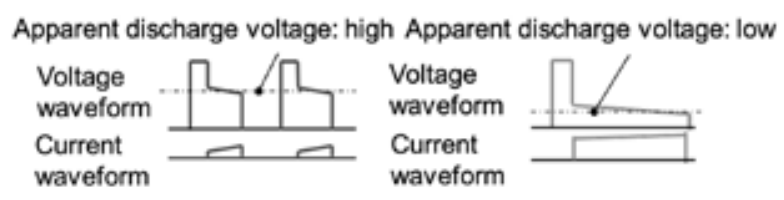

(b) Discharge threshold level: high

(c) Discharge threshold level: low

Fig. 16 Relationship between the formation state of the conductive layer and the discharge waveform

\section{CONCLUSION}

In this study, a modular-type wire discharge machine was developed to study the relationship between the conductive layer formed by electrical discharge and the machining characteristics. The conclusions obtained from the experiment are summarized as follows:

(1) Machining of insulating $\mathrm{Si}_{3} \mathrm{~N}_{4}$ ceramics is possible using the fabricated wire discharge machine.

(2) When the discharge current level for machining is set to high, the resulting conductive layer has a wavy-shaped surface.

(3) When the discharge current is set low and the second cut is applied, the surface roughness is improved.

(4) A phenomenon was observed in which the apparent discharge voltage was almost equal to the discharge threshold level.

(5) When the discharge threshold level for machining is set to low, a thick conductive layer is formed, and the machining speed is improved.

(6) The discharge threshold level is a key factor that affects the machining characteristics in the electrical discharge machining of insulating $\mathrm{Si}_{3} \mathrm{~N}_{4}$ ceramics. 


\section{Acknowledgement}

The authors would like to thank Prof. Yasushi Fukuzawa of the Nagaoka University of Technology for guiding us through this study. This study was supported in part by the Grants-in-Aid for Scientific Research (KAKENHI) from the Ministry of Education, Culture, Sports, Science and Technology [2004, Grant-in-Aid for Scientific Research (B); MEXT KAKENHI Grant Number 16360359].

\section{References}

1) Takehiro WATANABE:The Laser Beam as a Flexible Tool for Machining Ceramics,Vol.37,No.10, (2002),pp.793-798(in Japanese)

2) Kiyoshi SUZUKI, Tetsutaro UEMATSU and Manabu IWAI:Ultrasonic Grinding for Hard and Brittle Materials, Ceramics,Vol.37,No.10,(2002), pp.781-784(in Japanese)

3) Manabu WAKUDA:Abrasive Jet Machining of Engineering Ceramics, Ceramics,Vol.37,No.10, (2002),pp.803-806(in Japanese)

4) Mohri N., Fukuzawa Y., Tani T., Saito N., Furutani K. : Assisting Electrode Method for Machining Insulating Ceramics, Annals of CIRP,45(1),(1996), pp.201-204

5) Hiromitsu GOTOH, Takayuki TANI, Yasushi FUKUZAWA and Naotake MOHRI:WEDM for Insulating $\mathrm{Si}_{3} \mathrm{~N}_{4}$ Ceramics -Efforts at complex shape machining-,Journal of The Japan Society of Electrical
Machining Engineers, Vol.40,No.95,(2006), pp.162-168(in Japanese)

6) H.Gotoh,T.Tani,N.Mohri:Improvement of Machining Characteristics of WEDM on Insulating Ceramics, Proc. of 15thISEM,(2007),pp.145-148

7) Haruki OBARA:Lecture for Beginners Studying Electrical Machining (1) -Electric Discharge Circuits for Electric Discharge Machining-,Journal of The Japan Society of Electrical Machining Engineers, Vol.38,No.88,(2004),pp.29-35(in Japanese)

8) Taemin SHIN, Hisashi YAMADA, Naotake MOHRI, Katsushi FURUTANI, Yasushi FUKUZAWA, Takayuki TANI:Machining Phenomena in EDM of insulating Ceramics -Effect of Condenser Electrical Discharge-,Journal of The Japan Society of Electrical Machining Engineers, Vol.32,No.70,(1998),pp.1-7(in Japanese)

9) Takayuki TANI, Yasudhi FUKUZAWA, Katsushi FURUTANI, Naotake MOHRI:Machining Process of Insulating Ceramics by Electrical Discharge Machining,Journal of the Japan Society for Precision Engineering,Vol.63,No.9,(1997),pp.1310-1314(in Japanese)

10) Hiromitsu Gotoh, Takayuki Tani, Naotake Mohri, Yasushi Fukuzawa:Machining characteristics of WEDM on insulating $\mathrm{Si}_{3} \mathrm{~N}_{4}$ Ceramics-Observation of electrical Conductive layer and debris-, Proceedings of JSPE annual meeting 2007 fall(2007)pp.81-82(in Japanese)

11) Shoichiro KOIDE:Physics,SHOKABO CO.,Ltd., (1996),p.232(in Japanese) 